\title{
WORKPLACE REFORM IN NEW ZEALAND: THE CASE OF "TOMORROW'S SCHOOLS"
}

\author{
Phillip Capper and Roberta Hill ${ }^{\dagger}$ \\ New Zealand Post Primary Teachers' Association (PPTA) \\ ${ }^{\dagger}$ New Zealand Institute for Social Research and Development
}

This paper describes the development and structure of a research project, known as the 'Shared Decision Making Project', which is being funded by the secondary teachers' union, theNewZealand Post Primary Teachers' Association (PPTA). The PPTA has commissioned the New Zealand Institute of Social Research and Development (SR\&D), the Education Faculty at Victoria University of Wellington (VUW), and staff of the College of Education at the University of Illinois at Chicago(UIC) to undertake specific research tasks, and to act as consultants and supervisors to the whole exercise.

The project is using action research methods to explore management structures and decision making processes in New Zealand secondary schools, and seeks to document successful practice described in the context of a theoretical base; and to describe successful and unsuccessful experimental developments in a group of participant schools. These documentations and descriptions will be made available to all schools in New Zealand as a resource they can use in their own developmental activities.

The PPTA itself anticipates that the project will enable it to develop industrial and professional policies which are soundly based on research evidence.

The project is noteworthy in that it is the first major action research project initiated by a teachers' union in New Zealand; it is being co-ordinated by officers of the union; and its methodology includes some new applications of action research techniques.

\section{Origins of the Project}

PPTA interest in a project of this kind has its origins in the vastly changed environment in which it found itself operating in the beginning of the 90's. These changes arose from two interconnected strands. One can be described as a general change in the context of industrial relations and public policy reflecting in part government policies which included labour market deregulation and the desire to restrain government spending as central components. These began to develop with the election of the 1984 Labour Government in New Zealand and have been legislatively implemented by the general provisions of the State Sector Act 1988, and the Employment Contracts Act, 1991. Further legislation, such as the Industry Training Bill, is pending.
However at a deeper and less ideological level the new industrial environment is founded in fundamental changes in the nature of work and its context which have attended rapid economic and technological change, and specially in information technology, in the past decade.

The other strand involved the changes in the overall administration and management of the school system. These have partly been an education sector manifestation of the ideological and technological changes described above, but have also arisen from the application of public choice theory to education. Teachers themselves have remained interested in the specific need for an educational response to a vastly changed, and rapidly changing, world, but for the most part have not accepted that the application of the generality of current public and industrial relations policies assists in producing a useful response.

These changes have been legislatively implemented in New Zealand through the education sections of the 1988 State Sector Act and the 1989 Education Act. This reform process remains today in a very fluid state, as is demonstrated by the string of amendment bills which have followed the passage of the 1989 Act right up to the present.

The effect of this legislation on the activities of the teacher unions has been dramatic. Prior to 1988 industrial negotiations were almost exclusively concerned with the mathematics of relativities and cost of living indices. All other matters were the subject of consultative discussions and direct negotiations with the Department of Education and the government. For the most part administrative and managerial arrangements were not the subject of debate, and pre-existing structures were reflected in the design of salary scales.

The legislative reforms of $1988-1991$ not only proclaimed managerial and administrative change, but also made these matters the subject of negotiation in industrial forums. The white paper that foreshadowed the 1989 Education Act ('Tomorrow's Schools') went further and made policy statements about what forms of management the government wished to see introduced to schools.

Award (later collective contract) negotiations between 1988 and 1991 saw the employers aggressively seeking to 
have their favoured management models as articulated in government policy reflected in changes to the structure and coverage of documents. PPTA for its part recognized the need for reform, but found itself cast in the role of resisting what it saw as undesirable proposals by the employer, whilst basing its own counter-proposals on research most of which was foreign in origin.

In 1989 it commissioned a research report on the specific personnel policies contained in 'Tomorrow's Schools' ('The Munro Report') which was essentially reactive and a literature review. In 1991 the Executive commissioned a further report, still basically a literature review in its original conception, but pro-active in character - that is the union wished to produce a report which indicated positive directions for the good management of secondary schools. This initiative eventually evolved into the project described here.

\section{Evolution of the Project}

In August 1991 PPTA approached one of the present authors, Dr Roberta Hill, of the then Social Science Division of the DSIR (and since restructured into a Crown Research Institute for Social Research and Development, the SR\&D), and offered her the commission described above. Dr Hill described her action research orientation to the PPTA officials and out of these discussions the proposal evolved into what has now become Phase One of the fully developed project (see Fig. 1).

The original brief given to Dr Hill was to prepare a report which was to:

(a) develop a practical framework for shared decisionmaking in New Zealand secondary schools during a period of fundamental change in the education sector,

(b) generate the framework from the sharing of overseas and New Zealand knowledge and experience;

(c) achieve these goals by using "action research" methods. Such methods combine research with practical action and a participative process.

The 'Phase One' column of Figure 1 describes the process by which this report was to be produced.

However as the research brief was being developed a more ambitious concept evolved. It was felt that part (c) of the brief was unlikely to be achieved within the limited objective of the production of a report in a limited period of time. Furthermore PPTA officials were painfully aware of the existence of a seemingly endless procession of reports on school management practice which had had little impact primarily because of the lack of any follow up action following their distribution to schools already suffering from information overload.
Consequently part (c) of the original brief was expanded into Phases 2 and 3 as described below. With this significant change Dr Hill's report was no longer seen as the 'final word' but came to be redefined as a waypoint - a well developed proposition which was to be tested further by an extended period of advanced action research.

Action research has been applied to a variety of organizational and community contexts. These have ranged from schools and community development projects to industrial workplaces (see for example Blichfeldt, 1987; Baird and Mitchell, 1989; Taylor et al, 1990; Gustavsen, 1991; and URCOT, 1992).

Action research implies a theoretical sophistication which links substantive areas of social or technical explanation with thorough analysis of the process of change (URCOT, ibid).

In practice, the action research process involves groups of people working together to reflect upon their own circumstances, in order to bring about an improvement in their situation. This involves gathering and analysing data, followed by action to implement new strategies. (URCOT, ibid.)

In the present project the researchers - drawn from the PPTA, VUW, UIC, and SR\&D - not only observe and describe the experiences of the participating schools, but participate in the processes of reflection and change. Furthermore funds will be provided within the project budget to assist participating schools with their experiments by providing them with expertise, advice, and opportunities for professional development and networking. This builds on the Scandinavian idea of a network-based strategy for organisation development in which a programme of support is provided to groups of enterprises clustered into learning networks (Gustavsen, 1991). Phase Two will be a two year project and is expressed diagrammatically in column two of Figure 1.

Once Phase Two of the project had been developed it was a short step to Phase Three, which involves writing up the Phase One and Two outcomes in a way which can be distributed as a resource for all New Zealand secondary schools to use at their discretion when considering their own management and decision making structures and processes. This will occur as materials come available throughout the life of the project. Thus Phase Three begins with the circulation of the Phase One Report to all schools during November 1992.

The funding agency itself - the PPTA - expects to derive valuable information which will inform the future development of its industrial and professional policies, and which might be used to develop consensus with the employers in some areas at least.

The PPTA itself will remain the co-ordinator of the project throughout, guaranteeing its integrity through the 
Figure 1 The Research Process

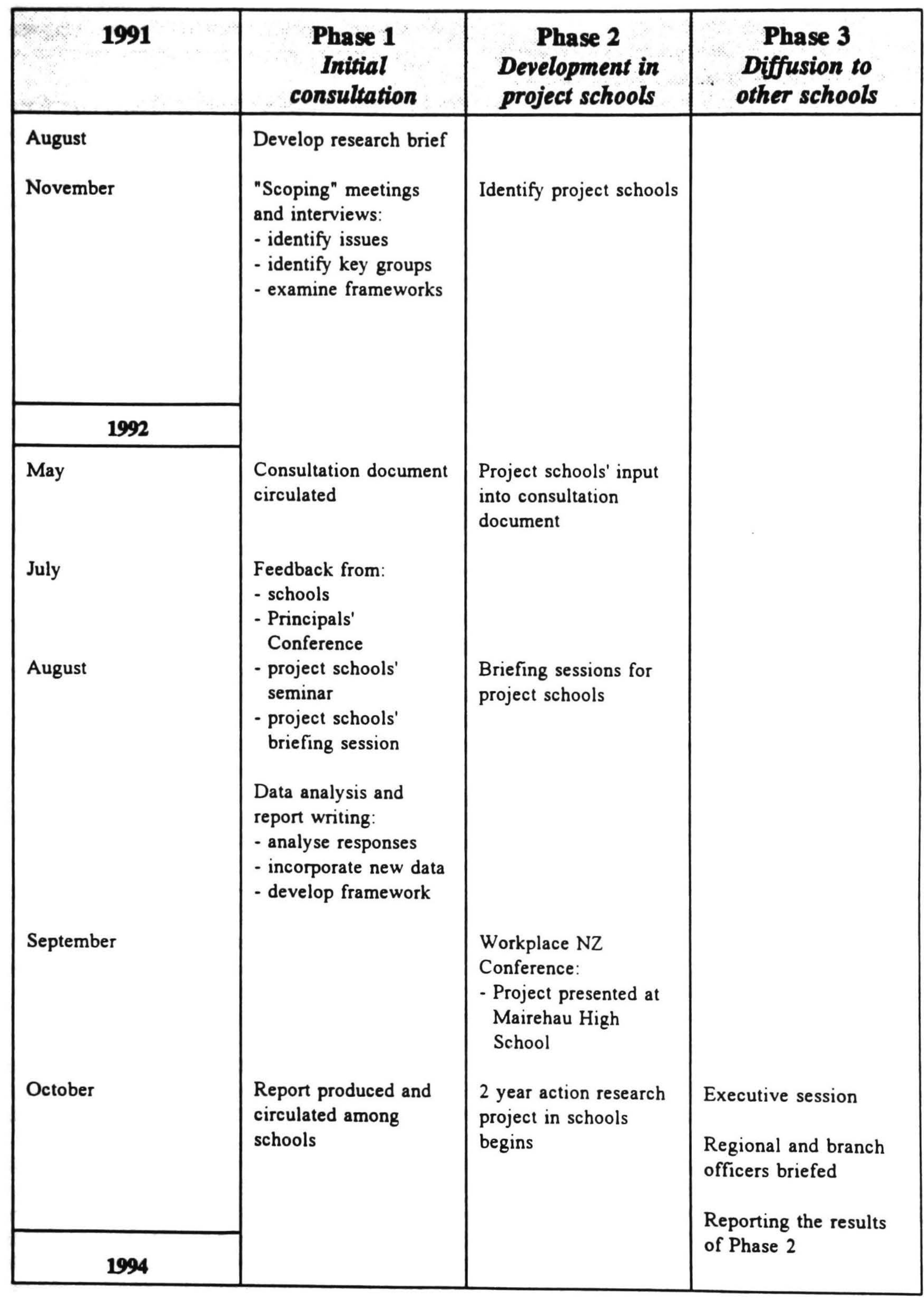


supervisory participation of the other commissioned agencies and an advisory committee comprising employer groups, along with teachers, principals, other unions and academics.

\section{A Report on Phase One}

The Phase One Report has been published (Hill, 1992). This section of the present paper offers a summary of it.

The report is based on an analysis of data drawn from a variety of sources during a series of iterative cycles of action research. It looks first at the nature of the changes faced by the school system, as described by the teachers and organizations which participated in the research but set in the context of current literature on education policy.

These changes are:

(a) the globalisation and consequent transformation of the New Zealand economy;

(b) technological change, which impacts both on the curriculum and pedagogical method;

(c) public pressure for involvement in educational decision making;

(d) the changed social environment in which schools operate;

(e) the contradictory forces of devolution and centralization in the legislation governing the education system; and

(f) changes in the industrial bargaining environment.

Teachers and others involved in the consultations clearly identified a number of ways in which these changes have impacted on their work and working environment. They can be listed as follows.

(a) The nature and pace of demands made on schools have changed rapidly both quantitatively and qualitatively, and continue to do so. These demands are increasing workloads and altering the kinds of skills required, especially amongst management.

(b) Support agencies are not providing schools with the levels of external support that were formerly available.

(c) There are clear signs of 'information overload'.

(d) A consequence of the foregoing factors is that decision making within the school has become a much more complex exercise.

(e) There have been significant changes in expectations, roles, and responsibilities. Teachers see the notions of accountability and the need to be 'transparent' about their professional actions to the communities they serve as exposing them to a mass of conflicting messages from formal and informal groupings whose roles, responsibilities, and basis for authority are not always clearly defined or understood, and some of whom are perceived as not having been adequately prepared for their tasks.

(f) Those consulted identified commonly experienced consequences in their work. Principals in particular are working much longer hours, but are spending less time exercising professional leadership. Both teachers and principals often perceive principals as becoming increasingly isolated from their teaching colleagues. Teachers themselves frequently note that they too are spending more time on administrative matters such as budgeting, and are able to devote less time to the concerns of individual students.

The role of the union and the place of industrial negotiations are also the subject of reappraisal. The present project itself is a manifestation of a changing selfperception of the union's role by its leadership, but the variety of reactions to it amongst members generally and those involved in the consultations in particular illustrates the generally fluid state of perceptions of exactly how the newly changed environment ought to work.

Some saw the project as an attempt by the union to lay the foundation of a 'union takeover' of schools, whilst others took precisely the opposite view that it constituted co-option of the union by management. This division of opinion echoes the similar debate over workplace reform in private sector industrial relations whereby, for example, many unions participated in, and indeed were instrumental in organizing, theWorkplace New Zealand Conference (Rotorua, September 1992), whilst representatives of others stood at the entrances to venues as a picket line.

Others amongst the teachers consulted regarded how decisions were made in schools as 'none of the union's business', whilst still others saw it as a positive act of strategic unionism and responsible professionalism. This latter view was clearly the majority position of the PPTA Executive which initiated the Project.

Consideration of all of the matters discussed in the foregoing has led many staff at all levels of existing school hierarchies to reconsider both the appropriateness of the currently predominant management practices in secondary schools; and of the so far incompletely implemented policies of 'Tomorrow's Schools'. However this does not mean that a common view exists about what models are appropriate. The consultations revealed a wide range of views, and a significant number who acknowledged that existing models are inadequate, but who had not yet formed an opinion of what practices ought to replace them. 
Furthermore there was a strong reactive response from many classroom teachers which can be summed up as a desire to be freed from existing administrative and decision making burdens in order to be left to concentrate on the needs of their own classes. Such wishes were but one of many attitudinal and structural inadequacies identified by some as representing barriers to effective decision making in secondary schools.

Having identified the issues confronting managers, staff, and unions in New Zealand secondary schools the report then considers the theoretical foundations and practical experience of workplace reform in industry. This is done not to provide answers for schools, but rather to clarify what questions they ought to be asking. It is argued that the issues of rapid change, including technological change, and restructuring, means that schools are facing many of the same issues being addressed in the private sector, even though schools have features which make them a unique type of institution which necessitates a search for sector specific answers. This section of the report also considers the argument for a changed union role in a workplace reform setting.

The report then goes on to argue that the participative practices and changed management structures now spreading through the private sector are, in broad conceptual terms, equally appropriate as a way of addressing the changed environment in which schools must now operate. Indeed they may be even more appropriate. A review of the education management literature shows the parallels in both problem definition and the postulation of solutions.

In particular the report points out that the major OECD review (1990), Schools and Quality, identified shared decision making as a fundamental prerequisite for effective school organization. This research showed that schools operate best in a framework of collaborative planning. shared decision making, and collegial work in an environment of experimentation and evaluation. Other factors associated with desirable school outcomes were a commitment to clearly and commonly identified norms and goals, and positive leadership in initiating and maintaining improvement.

Various sources are used to develop these arguments, but it is particularly noted that schools have tended to drift into hierarchical and bureaucratic modes of operation which, in the words of Clark and Meloy in their 1990 book Schools as Collaborative Cultures: Creating the Future Now "have sacrificed the freedom of their employees in favour of control over those employees to the disadvantage of both the employee and the organization".

The present research also revealed that student motivation and achievement are profoundly affected by the distinctive culture in each school. But another school specific factor is raised by UIC professor and project evaluator Julius Menacker (1992, pers. com), and confirmed by reference to a paper by former Hagley High
School principal Ros Heinz (1990). These writers argue that shared decision making in schools has a more fundamental purpose than merely effectiveness and efficiency. As Menacker writes, shared decision making processes and structures:

provide students with immersion into a truly democratic sub-society in which important decisions are not made by fiat, but rather through consultation and participatory management. In such an environment students are witnesses to and directly affected by the democratic process in action, rather than simply being told what it is supposed to be by their teachers. The school, as one of several 'people changing' institutions, should naturally operate this way.

Having made the case for shared-decision making the report goes on to identify the key features of such practices. These are summarized in Figure 2. The report concludes by describing the strategy for implementation which constitutes Phase Two of the project.

\section{Phase Two: A Progress Report}

As soon as a decision was made to proceed with Phase Two of the project some fundamental structural decisions were made by the project team. The initial decision was that a range of types of New Zealand schools should be invited to participate, and that a total of 18 schools should be recruited, organized into three clusters to facilitate observation and networking. A further decision was that an active attempt should be made to recruit some schools which were likely to be sceptical about the project.

The regions finally selected for the location of clusters - Northland, Wellington, and Canterbury - were identified after a call for expression of interest showed where enthusiasm was strongest. A lengthy period of briefing, consultation and negotiation took place, during which some schools withdrew. As the detail of the project became more clearly defined, and the resource requirements of the task were delineated, it was decided to reduce the number of participants to a sustainable total.

Recruitment was therefore stopped when 13 schools had agreed to participate, 5 of which had not been amongst those originally expressing interest. The schools are:

\section{NORTHLAND \\ Broadwood Area School \\ Taipa Area School \\ Otamatea High School \\ Mahurangi College}

\section{WELLINGTON \\ Makoura College \\ Porirua College \\ Naenae College \\ Onslow College}


Figure 2. Decision-making continuum: a framework for change

\begin{tabular}{|c|c|c|}
\hline & $\begin{array}{c}\text { FROM } \\
\text { "TOP DOWN" }\end{array}$ & 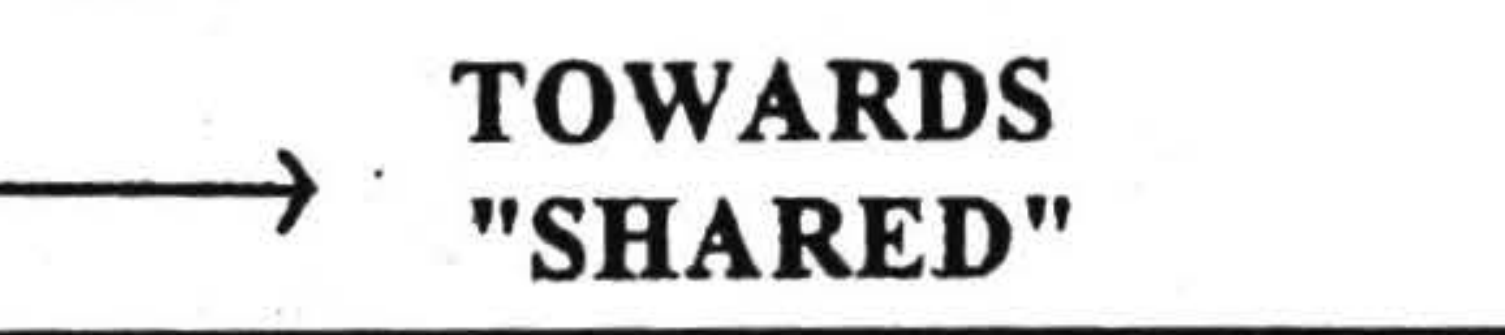 \\
\hline Policy Development & $\begin{array}{l}\text { Reactive } \\
\text { - pragmatic response to } \\
\text { social, political, } \\
\text { economic influences }\end{array}$ & $\begin{array}{l}\text { Proactive, strategic vision } \\
\text { - commitment to clearly } \\
\text { identified values, goals } \\
\text { - collaborative planning }\end{array}$ \\
\hline Organisational Structure & A pyramid structure & A flattened structure \\
\hline Leadership & $\begin{array}{l}\text { Authoritarian control by } \\
\text { management }\end{array}$ & $\begin{array}{l}\text { Consensus-forming with } \\
\text { managers as facilitators }\end{array}$ \\
\hline Authority & $\begin{array}{l}\text { Centralised (accountability to } \\
\text { top of hierarchy) }\end{array}$ & Shared accountability \\
\hline Power Relations & $\begin{array}{l}\text { Manipulation, control, } \\
\text { adversarial }\end{array}$ & Negotiation, consensual \\
\hline Flow of Information & $\begin{array}{l}\text { To/from top of hierarchy } \\
\text { - many layers to pass } \\
\text { through } \\
\text { - limited access }\end{array}$ & $\begin{array}{l}\text { Flows to "who needs it" } \\
\text { directly from "who has it" } \\
\text { - few layers } \\
\text { - open access }\end{array}$ \\
\hline Decision Forum & $\begin{array}{l}\text { Individual - dependent on } \\
\text { formal status. } \\
\text { Limited access } \\
\text { Recommends (through } \\
\text { hierarchy) }\end{array}$ & $\begin{array}{l}\text { Group - dependent on } \\
\text { relevance of skills and roles } \\
\text { Structured to include diversity } \\
\text { of perspectives and needs } \\
\text { Has delegated authority and } \\
\text { power to decide }\end{array}$ \\
\hline Who is part of decision? & $\begin{array}{l}\text { Determined by leader (which } \\
\text { may be "consult everybody") }\end{array}$ & $\begin{array}{l}\text { Determined by "group" } \\
\text { (which may be authority } \\
\text { delegated to one person) }\end{array}$ \\
\hline $\begin{array}{l}\text { Response to new } \\
\text { technologies and policies }\end{array}$ & Custom and practice & Change and innovation \\
\hline Staff Development & $\begin{array}{l}\text { Appraisal for control and } \\
\text { competency measurement } \\
\text { Rigid roles } \\
\text { Supervision } \\
\text { Training - discrete and } \\
\text { episodic }\end{array}$ & $\begin{array}{l}\text { Appraisal to identify } \\
\text { development needs } \\
\text { Continuous role } \\
\text { redefinition } \\
\text { Participation } \\
\text { Learning - integrated and } \\
\text { continuous } \\
\end{array}$ \\
\hline Process & $\begin{array}{l}\text { Closed. No opportunity to } \\
\text { check for bias }\end{array}$ & Open. Subject to scrutiny \\
\hline
\end{tabular}




\section{CANTERBURY}

Rangiora High School

Mairehau High School

Avonside Girls High School

Hagley High School

Ashburton College

Upon entry participating schools were provided with copies of the project protocol which is attached as Appendix Two.

Following briefing visits to most of these schools by project personnel an initial activity was offered which consisted of a seminar for each cluster in which a detailed case study of a school with a well-developed shared decision making structure, St Helena Secondary College in Melbourne, was presented by the principal, Ken Cunningham, and discussed by participants.

As a direct consequence of this seminar two schools have mounted three project-related experiments. Mairehau High School has restructured its Board of Trustees to increase the number of staff and student members such that staff, parent, and student membership are of equal numbers. Given current legislation the additional members are in fact observers with speaking rights, but it is hoped that this will not prevent full participation in board business.

Mairehau is also intending to start work on the creation of a collaboratively developed peer appraisal scheme for teachers in 1993.

In the third programme Avonside Girls' High School is in the process of reorganizing its curriculum organization into faculties and restructuring its curriculum management.

All three of these programmes will be observed and recorded as part of the project, and they will be supported by its Professional Development budget.

A further project activity was the offering of Mairehau High School as a demonstration project for the Workplace New Zealand Conference. The school was visited by a number of public and private sector managers and union officials, and they were presented with sessions on the management of the school and the present project. In the ensuing discussions a mutually supportive link was established between the principal and a private sector manager.

Following this demonstration the project co-ordinator in Mairehau High School and the two project co-ordinators from PPTA national office attended the Workplace New Zealand Conference in Rotorua at the end of September.

In October and November entry profiles were carried out in project schools. These profiles are intended to give the researchers a detailed understanding of the participating institutions, and also to give the schools feedback which might assist them to identify areas in which areas useful project related experiments might be carried out.

There are four components to the entry profile. Questionnaires were designed for administration to samples of staff, students, parents, and Board members; a portfolio of significant school documents was collected; a decision tracking exercise was carried out whereby sample Board and staff meeting decisions were tracked to their origins within the school, and also forward to how they were implemented; and in depth interviews were conducted with small samples of staff, students, and parents, as well as the principal, the board chairperson, and branch PPTA officials.

This data is currently being analysed and will form the basis of a report to each school and an overview report of patterns noted in all 13 schools. It is intended to repeat the exercise for comparative purposes at the end of the two year period.

With the publication of the Phase One Report project schools will have entered the 1993 school year with all preliminary documentation completed, and it is anticipated that at this point the levels of activity will increase markedly. Indeed the original intention was that school activities should only begin at this point, so the programmes already initiated and described above are indicative of a high level of enthusiasm in some of the participating schools.

\section{Conclusion}

From the point of view of the PPTA Executive this project represents a considerable investment in what it sees as a major exercise in strategic unionism. Through the project PPTA hopes to make a positive contribution to school development and adaptation to changing times; to establish a better knowledge base for its own policies; to assist in developing better shared understandings between the union and the employer at the bargaining table; and to help redefine the role of the union in the reformed workplace of the 1990's.

As has been indicated this commitment is controversial, and the debate over whether these sorts of activities are a legitimate use of members' subscriptions; and whether the union's involvement in such an exercise and the model of decision making being proposed represents a sensible redefinition of the union's role, or whether it is instead an abdication of the union's traditional purpose of protecting workers' rights and conditions, remains very much alive.

In any event this project is an exemplar of the sorts of activities associated with the new concept of unionism which is being adopted by many New Zealand unions, and equally vigorously opposed by others. During the time span of the project one can expect many of these issues to become better clarified both in education and elsewhere. 


\section{References}

Baird, J. \& Mitchell, I.J. (Eds) 198). Improving the Quality of Technologyand LEarning:AnAustralian Case Study -The Peel Project. Melbourne: Monash University.

Blichfeldt, J.F. 1987. A Case of Action Research. In: Steffan Selander (ed) Perspectives on Action Research. Stockholm: Stockholm Institute of Education, Department of Educational Research.

Clark, D.L. \& Meloy, J.M. 1990. Recantin Bureaucracy: A democratic Structure for Leadership in Schools. In: A. Lieberman (ed). Schools as Collaborative Culture: Creating the Future Now. School Development and the Management of change Series. 3. Hampshire. Falmer.

Gustavsen, B. 1991. The LOM program: a Network Based Strategy for Organisation Development in Sweden. In: Research in Organisation Change and Development. 5. JAI Press. pp290-1.

Heinz, R. 1990. Towards Pluralism and Democracy: The Administration of an Inner City School. In: H.Lauder, and C.Wylie, (ed). Towards Successful Schooling. Lewis. Falmer.

Hill, R. 1992. Managing Today's Schools: The Case for Shared-Decision Making. A report prepared for the New Zealand Post Primary Teachers' Association. Christchurch. SR\&D.

MenackerJ. 1992. Personal Communication.

Munro, R. 1989. The Munro Report: Research into the Personnel Provisions of Tomorrow's Schools. PPTA, February.

OECD 1990Schools and Quality. Paris: OECD

Taylor, C.N. et al 1990. Social Assessment: Theory, Process \& Techniques. Studies in Reserouce Managment. No.7 Canterbury Centre for Resource Management.

URCOT 1992. Union Research Centre on Office Technology: Research Program 1992. UROT: Melbourne. 